\title{
EDITORIAL/ EDITORIAL
}

DOI: 10.12957/demetra.2015.16607

\section{Alimentação e nutrição: um campo científico realmente interdisciplinar?}

\section{Food and nutrition: a really interdisciplinary scientific field?}

Multi, inter ou transdisciplinar. Assim vem sendo identificado o campo científico da Alimentação e Nutrição em diversos documentos que circulam nesse espaço da sociedade. O "Documento da Área Nutrição na CAPES”, por exemplo, é claríssimo ao tratar dessa temática ao afirmar, em seu item "interdisciplinaridade", que:

Alimentação e Nutrição é um campo de produção de conhecimentos e saberes e de formação de cientistas no qual diferentes disciplinas e vertentes teórico-metodológicas se articulam em tensões e consensos. Considera-se, portanto, que propostas de programas de pós-graduação organizadas em torno dos objetos "nutrientes, alimentos e comida com foco no processo saúde-doença-cuidado" deverão ser acolhidas neste espaço institucional. Dentro da perspectiva da interdisciplinaridade, poderão ser aceitos na área de Nutrição Programas ordenados em torno dos seguintes núcleos de saberes: Nutrição Clínica (presença de disciplinas e conteúdos voltados para a terapêutica do conjunto das patologias no âmbito individual), Nutrição Básica e Experimental (contando com disciplinas e conteúdos voltados a estudos com seres humanos e animais como bioquímica, fisiologia, genética, entre outras), Ciência e Tecnologia de Alimentos Aplicadas à Saúde (disciplinas e conteúdos do âmbito da composição química e desenvolvimento de alimentos), Alimentação e Nutrição em Saúde Coletiva (disciplinas e conteúdos como epidemiologia, políticas, planejamento e gestão em saúde, entre outras) e Ciências Humanas e Sociais em Alimentação e Nutrição (disciplinas e conteúdos como sociologia, antropologia, epistemologia, alimentação de coletividades, entre outras).

São culturas científicas muito distintas operando diante de problemas que transcendem o paradigma das disciplinas. Há o mundo das Ciências da Natureza - em particular a Biomedicina, expressa nos estudos realizados no âmbito da Nutrição Clínica, da Nutrição Básica e Experimental, da Nutrição e Alimentos ou da Epidemiologia Nutricional -, que encontra chão no consumo rápido de informações recentes relativas a fenômenos universais, com seus consensos razoavelmente 
estabelecidos caracterizando uma ciência normal, como nos diz Bachelard. E há as Humanidades, com destaque para as ciências que se dirigem àquilo que diz respeito às relações sociais imersas, inexoravelmente, em valores, interesses e vontade de poder, relativas à subjetividade, ao qualitativo, ao específico e local. Mundos que podem e devem dialogar sem, contudo, deixar de ser o que são: universos distintos.

A pluralidade epistemológica impõe-se para que o campo da Alimentação e Nutrição possa se realizar em sua plenitude. A materialização do reconhecimento definitivo dessas diferenças exige a utilização de instrumentos de avaliação do trabalho realizado apropriados para cada um desses espaços ou, em outras palavras, capazes de identificar o que há de qualidade sendo publicado em cada um desses lugares.

Já no que tange à avaliação dos trabalhos científicos realizados nesses diferentes modos de produção de conhecimentos e saberes, há controvérsias. Descontando o imenso desafio que significa avaliar ciência, uma questão pode ser colocada na mesa de debates: é possível que um único instrumento possa avaliar procedimentos científicos tão diferentes?

Por mais óbvia que seja a resposta, a CAPES e, em particular, a assim denominada Grande Área da Saúde, determina que haja apenas e tão somente um modelo de procedimentos para avaliação do conhecimento científico divulgado através de periódicos científicos. Imperam aí os cálculos de fatores de impactos e outros índices bibliométricos que conferem notas maiores para publicação em revistas que divulgam conhecimento de rápido consumo e cujo valor se extingue em pouquíssimo tempo. Lembra o que Lipovetsky denomina de "hipermodernidade": um mundo "fast", no qual o consumo de agora já traz seu imediato desuso e a necessidade imperiosa de substituição por um novo produto.

Mergulhados no mercado voraz - e cada vez mais concentrado, dos periódicos científicos em mãos de prósperas editoras privadas -, os pesquisadores e estudantes da lida biomédica veem o tempo passar velozmente, na corrida pela próxima publicação Al (100 pontos) ou A2 (85 pontos) ou B1 (70 pontos). Alcançam tais patamares vários desses agentes, uma vez que isso parece ter se consolidado como um valor favorável em sua cultura científica, a despeito de críticas sérias ao modelo, como se pode reconhecer em alguns manifestos que circulam mundialmente, a saber: Bibliometrics: The Leiden Manifesto for researchmetrics, ${ }^{1}$ publicado em abril último na Nature e o DORA - The San Francisco Declarationon Research Assessment. ${ }^{2}$

1 Disponível em: http://www.nature.com/news/bibliometrics-the-leiden-manifesto-for-researchmetrics-1.17351. Acesso em: 23 maio 2015.

2 Disponível em: http://am.ascb.org/dora/. Acesso em: 23 maio 2015. 
Os trabalhos elaborados no campo das Ciências Humanas têm por base, em geral, estudos clássicos, praticamente todos livros produzidos há décadas, séculos e até milênios. Fazem uso também de artigos publicados em periódicos científicos para divulgação do conhecimento gerado, sendo esses veículos avaliados não por meio de indicadores bibliométricos, mas através das bases indexadoras em que se encontram inseridos. Outro mundo, outros instrumentos de avaliação.

Retornando à interdisciplinaridade, ou seja, aos espaços onde múltiplas disciplinas e culturas científicas se encontrariam, o que temos? O desencontro! Pesquisas científicas que se voltam para objetos que somente podem ser abordados por meio de estudos que partem dos fundamentos teórico-metodológicos próprios das Ciências Humanas, sendo avaliadas através de indicadores bibliométricos dos periódicos nos quais os artigos correspondentes são publicados.

Para que se possa visualizar as implicações nefastas desses procedimentos, ilustramos com informações disponíveis na página eletrônica intitulada "WebQualis", na qual é disponibilizada a classificação das revistas nas quais os pesquisadores publicam seus artigos. A revista Avaliação (UNICAMP), que publica, prioritariamente, trabalhos relacionados com os temas da "avaliação da educação superior" - ou seja, que lida com objetos de grande relevância para as universidades, para a ciência - é classificada como A2 (85 pontos) na área de avaliação da Educação e como B4 (15 pontos) na área de avaliação da Nutrição. Isso significa dizer que a Nutrição não valoriza essa temática, já que a qualidade da revista está atestada pelo campo de máximo conhecimento desse assunto: a Educação. Significa também que o pesquisador que se dedicar a estudar questões relativas à formação superior em Nutrição terá que publicar quatro artigos nessa revista para alcançar a pontuação de um único artigo publicado em periódico biomédico classificado como A2 na Nutrição, Por outra via, o pesquisador subordinado aos critérios avaliativos da área de Nutrição na CAPES que tem seus estudos situados no campo das Humanidades e que vem dedicando seus esforços para tratar de temas ligados à educação superior deverá trabalhar quatro vezes mais que aquele situado no âmbito da biomedicina.

Docentes inseridos em programas de pós-graduação que tomaram os rumos da pesquisa em Ciências Humanas e Alimentação e em Políticas de Alimentação e Nutrição estão deixando os objetos de estudos aí situados para buscar os espaços mais valorizados de produção de conhecimentos, como a Epidemiologia Nutricional, por exemplo. Estamos diante, portanto, de um processo de esvaziamento da interdisciplinaridade que poderá ser revertido com a simples adoção de critérios de avaliação mais adequados às culturas que precisam conviver e interagir.

Cabe lembrar que Edgar Morin nos chama a atenção para problemas que transbordam ao paradigma das disciplinas, tratando-os em sua complexidade. A fome é uma constante no mundo cada vez mais inundado de conhecimentos científicos e de tecnologias inovadoras. Seu extremo 
oposto e irmã siamesa - a obesidade - é apresentada como a nova epidemia mundial que avança a passos largos e diante da qual também as disciplinas têm mostrado seguidas insuficiências.

Assumir a complexidade exigida do pensamento, religando o que está fragmentado nas ciências e nos outros lugares sociais é um passo importante. Faz parte desse passo aproximar as Ciências Biomédicas das Humanidades, valorizando-as em suas especificidades e construindo a Alimentação e Nutrição mais que interdisciplinar: como um campo complexo.

Shirley Donizete Prado

Fabiana Bom Kraemer

Editoras 